\title{
Overexpression of CD133 enhances chemoresistance to 5-fluorouracil by activating the PI3K/Akt/p70S6K pathway in gastric cancer cells
}

\author{
YOULONG ZHU*, JIWEI YU*, SHOULIAN WANG, RUIQI LU, JUGANG WU and BOJIAN JIANG \\ Department of First General Surgery, Shanghai Third People's Hospital, School of Medicine, \\ Shanghai Jiaotong University, Shanghai 201900, P.R. China
}

Received June 30, 2014; Accepted August 22, 2014

DOI: $10.3892 / o r .2014 .3488$

\begin{abstract}
CD133 has been reported to be associated with chemoresistance in various cancer cells. The efficacy of 5-fluorouracil (5-FU), an important chemotherapeutic agent for advanced gastric cancer (GC), is limited by 5-FU resistance. Hence, the present study investigated the function of CD133 in 5-FU resistance in human GC cells. We isolated $\mathrm{CD}_{133}{ }^{+} \mathrm{GC}$ cells by immunomagnetic cell sorting and CD133 expression was modulated by transfection of CD133 gene or CD133 small interfering ribonucleic acid. To assess the 5-FU cytotoxicity, Cell Counting Kit-8 was used. Expression of CD133, P-glycoprotein (P-gp), B-cell lymphoma 2 (Bcl-2), Bcl-2-associated $X$ protein (Bax), phospho-Akt (p-Akt) and phospho-p70S6 kinase (p-p70S6K) were analyzed by western blotting. CD133, P-gp, Bcl-2 and Bax messenger ribonucleic acids were evaluated using semi-quantitative reverse transcriptase-polymerase chain reaction. Cell apoptosis was assessed by Hoechst 33258 staining. CD133 ${ }^{+}$cells were more resistant to 5-FU than CD133-cells, and showed higher expression of P-gp and Bcl-2 with lower expression of Bax. Furthermore, CD133 silencing enhanced 5-FU cytotoxicity and apoptotic characteristics, whereas CD133 overexpression increased 5-FU resistance. CD133 silencing and activation directly decreased and increased the expression of P-gp, Bcl-2, p-Akt and p-p70S6K, respectively. Notably, Akt inhibition by LY294002 restored the 5-FU cytotoxicity suppressed by CD133 overexpression, while Akt activation by epidermal growth factor reversed the 5-FU cytotoxicity enhanced by CD133 silencing. Therefore, CD133 may inhibit 5-FU-induced
\end{abstract}

Correspondence to: Professor Bojian Jiang, Department of First General Surgery, Shanghai Third People's Hospital, School of Medicine, Shanghai Jiaotong University, Shanghai 201900, P.R. China E-mail: jenniferyu919@126.com

${ }^{*}$ Contributed equally

Key words: gastric cancer, PI3K/Akt/p70S6K, 5-FU resistance, CD133 apoptosis by regulating the expression of $\mathrm{P}-\mathrm{gp}$ and $\mathrm{Bcl}-2$ family mediated by phosphoinositide 3-kinase/Akt/p70S6K pathway in GC cells.

\section{Introduction}

Gastric cancer (GC) is the fourth most common type of cancer worldwide (1). Following lung cancer, GC is also the second leading cause of cancer-related mortality in Asia. Most GC patients who undergo surgical resection and postoperative adjuvant therapy die due to tumor recurrence and metastasis, with a 5-year overall survival of no more than $50 \%$ in China (2). Chemoresistance and ineffectiveness of radiotherapy are leading causes of therapy failure in GC patients. Hence, elucidating the mechanism of chemoresistance will further enable us to choose appropriate chemotherapeutic drugs to treat GC, thereby improving the survival of GC patients.

CD133 is a transmembrane glycoprotein and its expression in cell surface downregulates quickly as cell differentiated (3). CD133 has been used widely as a marker to identify cancer stem cells (CSCs) in colon, lung, brain and pancreas (4-7). Furthermore, CD133 expression is correlated with chemoresistance and early recurrence of GC (8). Earlier studies on CD133+ cancer cells displayed resistance to many chemotherapeutic agents such as paclitaxel (9), etoposide, 5-fluorouracil (5-FU) and cisplatin $(5,10)$. Furthermore, our previous study (11) showed that $\mathrm{CD} 33^{+} \mathrm{GC}$ cells were resistant to 5-FU. Although it has been reported that CD133 plays a key role in chemoresistance, its cellular mechanisms remain unclear. Thus, we performed further research to elucidate these mechanisms.

A number of cellular mechanisms that contribute to chemoresistance include upregulation of the multidrug-resistance (MDR) gene product and B-cell lymphoma 2 (Bcl-2) protein and its family members. Bcl-2 primarily mediates its pro-survival effects by binding to the pro-apoptotic proteins Bcl-2-associated $\mathrm{X}$ protein (Bax) and inhibiting its ability to release apoptogenic proteins such as cytochrome $c$ from the mitochondria (12). The overexpression of P-glycoprotein (P-gp) has been most extensively studied in MDR. Preliminary studies have attributed the high expression levels of specific adenosine triphosphate-binding cassette drug transporters to the increased resistance of $\mathrm{CD}_{133}{ }^{+}$cancer cells to chemothera- 
peutic agents $(13,14)$. In addition, Ma et al demonstrated that $\mathrm{CD}_{133^{+}} \mathrm{CSC}$ s appear to express higher levels of Bcl-2 than their CD133- counterparts in the human hepatocellular cancer cell line Huh7 (15).

Akt, a serine/threonine kinase, is a key molecule in protecting cells from apoptosis, and the Akt-mediated survival signaling pathway is an attractive target for cancer chemotherapy $(16,17)$. The expression of Akt is altered in various types of human tumor and this aberrant expression may contribute to chemoresistance (18-20). Akt-mediated chemoresistance is likely to result from overall anti-apoptotic activity of Akt and activation of the phosphoinositide 3-kinase (PI3K) signaling cascade, which leads to MDR.

Increasing evidence strongly suggests the functional association of $\mathrm{CD}_{133}{ }^{+} \mathrm{CSC}$ with Akt signaling. CD133 ${ }^{+}$tumor cells derived from hepatoma, colon cancer and neuroblastoma consistently displayed increased phospho-Akt (p-Akt) levels compared with matched CD133- tumor cells $(15,21,22)$. However, very few similar studies were reported for GC cells. Based on the coincidental finding of $\mathrm{CD}_{133^{+}}$cancer cells being resistant to chemotherapeutic induced apoptosis, the present study investigated whether CD133 expression serves a functional role in triggering MDR in GC cells. To investigate this potential relationship, low-expressing CD133 cell lines (SGC7901 cells) were employed (23). To overcome such chemoresistance, it is necessary to define the CD133-dependent molecular pathway and elucidate the optimal blocking strategy. Therefore, identification of suitable biomarkers for predicting patient prognosis and chemosensitivity is important for improving the therapeutic effects for patients with advanced GC.

The present study investigated the role of CD133 in the expression of P-gp and Bcl-2 and their family-mediated $\mathrm{PI} 3 \mathrm{~K} / \mathrm{Akt} / \mathrm{p} 70 \mathrm{~S} 6 \mathrm{~K}$ pathway inducible chemoresistance and to overcome this resistance by small interfering ribonucleic acid (siRNA) and/or 5-FU/LY294002 combination treatment.

\section{Materials and methods}

Chemicals. LY294002, epidermal growth factor (EGF) and 5-FU were purchased from Sigma (St. Louis, MO, USA).

Cell lines and cultures. Human GC cell lines SGC7901 and MKN45 were provided by the Shanghai Institute of Cell Biology, CAS (Shanghai, China). Cells were maintained in RPMI-1640 culture medium supplemented with $100 \mathrm{~g} / \mathrm{ml}$ streptomycin, $100 \mathrm{U} / \mathrm{ml}$ penicillin and $10 \%$ fetal bovine serum (both from HyClone, USA) at $37^{\circ} \mathrm{C}$ in a humidified atmosphere containing $5 \%$ carbon dioxide.

Immunomagnetic cell sorting. The cells were subcultured every 2-3 days. The third to fifth subcultures were harvested, and $\mathrm{CD} 133^{+} \mathrm{GC}$ cells were isolated utilizing a CD133 immunomagnetic cell sorting kit (Miltenyi Biotec, Bergisch Gladbach, Germany). The $\mathrm{CD} 133^{+}$cells were cultured in serum-free 1640 medium at $37^{\circ} \mathrm{C}$ in a humidified atmosphere containing $5 \%$ carbon dioxide $(23,24)$.

Liposome-mediated siRNA silencing of CD133. CD133-specific siRNA fragments were designed and synthesized from the
CD133 gene sequence (Shanghai GenePharma, Shanghai, China); sense strand, 5'-GUCCUUCCUAUAGAACAAUTT-3' and antisense strand, 5'-AUUGUUCUAUAGGAAGGACTT-3'. A non-specific siRNA sequence was synthesized as a negative control; sense strand, 5'-UUCUCCGAACGUGUCACGUTT-3' and antisense strand, 5'-ACGUGACACGUUCGGAGAATT-3'. Unsorted SGC7901 cell concentration was adjusted to $1.5 \times 10^{5}$ cells $/ \mathrm{ml}$ and spread on three 6 -well plates $(2 \mathrm{ml} /$ well $)$ (control, negative control group; and CD133, siRNA group), and cultured overnight. Transfection solution A was prepared as follows: the siRNAs were dissolved in deionized water at $20 \mu \mathrm{mol} / \mathrm{l}$ and mixed with RPMI-1640 at a ratio of 10:250 $\mu \mathrm{l} /$ well. Transfection solution B was prepared by mixing Lipofectamine 2000 (Invitrogen, Carlsbad, CA, USA) and RPMI-1640 at a ratio of 5:250 $\mu \mathrm{l} /$ well. After $5 \mathrm{~min}$, the two transfection mixtures were mixed together and allowed to stand for $20 \mathrm{~min}$. This transfection solution of CD133 siRNA was added to the corresponding wells. RPMI-1640 (500 $\mu \mathrm{l} /$ well) was added to the uninterfered group as a control. After 24-h of transfection, the solution was exchanged with serum-containing RPMI-1640.

Stable transfection of CD133. Cells were cultured up to a 60-80\% confluence state. The CD133 complementary deoxyribonucleic acid (cDNA) plasmid was extracted with plasmid extraction pail (Qiagen, Düsseldorf, Germany) and transfected using Lipofectamine ${ }^{\circledR}$ LTX reagent (Invitrogen, Tokyo, Japan) in accordance with the manufacturer's protocol. Following transfection, cells were cultured for $72 \mathrm{~h}$ and intermediate samples were collected at 24 and $48 \mathrm{~h}$ for further analysis.

Western blotting. Quantified protein lysates were resolved on sodium dodecyl sulfate-polyacrylamide gel electrophoresis, transferred onto polyvinylidene difluoride membrane (Millipore, Billerica, MA, USA), and immunoblotted with mouse anti-human CD133/1 (1:100; Miltenyi Biotec), P-gp (1:500; Santa Cruz Biotechnology, Inc., Santa Cruz, CA, USA), rabbit anti-human P-Akt (Ser473, 1:1,000), Akt (1:1,000), Bcl-2 $(1: 1,000)$, Bax $(1: 1,000)$ and glyceraldehyde-3-phosphate dehydrogenase (GAPDH) (1:2,000) (Cell Signaling Technology Inc., Boston, MA, USA). After immunoblotting, lysates were incubated with horseradish peroxidase-labeled goat or mouse anti-rabbit immunoglobulin G secondary antibody $(1: 2,000$; Jackson, Mukilteo, WA, USA) at room temperature. Blots were visualized using enhanced chemiluminescence (Amersham Biosciences Inc., Piscataway, NJ, USA).

Semi-quantitative reverse transcriptase-polymerase chain reaction ( $s q R T-P C R$ ). Total ribonucleic acid (RNA) was extracted using TRIzol reagent (Invitrogen). The extracted RNA (500 ng) was reverse-transcribed into cDNA using a commercial kit (Takara Bio Inc., Otsu, Shiga, Japan) under the following conditions: $42^{\circ} \mathrm{C}$ for $30 \mathrm{~min}, 99^{\circ} \mathrm{C}$ for $5 \mathrm{~min}$ and $5^{\circ} \mathrm{C}$ for $5 \mathrm{~min}$. The cDNA was used as a template for PCR amplification with forward and reverse primers (Shanghai Sangon, Shanghai, China), as shown in Table I. The primer annealing temperatures were: $\mathrm{CD} 133$ at $57^{\circ} \mathrm{C}$, multidrug resistance protein 1 at $72^{\circ} \mathrm{C}, \mathrm{Bcl}-2$ at $72^{\circ} \mathrm{C}$ and $\mathrm{Bax}$ at $72^{\circ} \mathrm{C}$. GAPDH was used as an internal control for the PCR reaction (Shanghai Sangon) and the annealing temperature was $55^{\circ} \mathrm{C}$. The final products of RT-PCR amplification were checked by agarose 
Table I. Primer sequences.

\begin{tabular}{llr}
\hline Gene & \multicolumn{1}{c}{ Primer sequence (5'-3') } & $\begin{array}{c}\text { Length } \\
\text { (bp) }\end{array}$ \\
\hline CD133 & $\begin{array}{l}\text { F: TTACGGCACTCTCACCT } \\
\text { R: TATTCCACAAGCAGCAAA }\end{array}$ & 172 \\
MDR1 & F: GCTTATGCGAAAGCTGGAGCAGTT & 151 \\
& R: TGGCCGTGATGGCTTTCTTTATGC & \\
Bcl-2 & F: TTGGATCAGGGAGTT & 295 \\
& R: TGTCCCTACCAACCA GAAGG & \\
Bax & F: GTTGCCCTCTTCTACTTTG & 142 \\
& R: AGCCACCCTGGTCTTG & \\
GAPDH & F: ACGGATTTGGTCGTATTGGGCG & 197 \\
& R: CTCCTGGAAGATGGTGATGG & \\
\end{tabular}

F, forward; R, reverse.

gel electrophoresis (Bio-Rad, Hercules, CA, USA). The results were photographed on a gel imaging system (Bio-Rad) and the relative gray value of each DNA band was estimated. Each measurement was repeated thrice.

Cell proliferation and cytotoxicity assay. The Cell Counting Kit-8 (CCK-8) assay was used to assess the cell viability. Cells were seeded onto 96 -well plates at a concentration of $8 \times 10^{3} /$ well and incubated overnight under the usual culture conditions. Cells were exposed to each of 5-FU at various concentrations $(0,0.1,1,10,100$ and $1,000 \mu \mathrm{M}$; dissolved in dimethyl sulfoxide). After $10 \mu \mathrm{l}$ of CCK- 8 solution was added in each well, the plates were incubated for $1 \mathrm{~h}$ at $37^{\circ} \mathrm{C}$. The absorbance of individual wells was read at $490 \mathrm{~nm}$ (test wavelength) and $530 \mathrm{~nm}$ (reference wavelength) using a microplate reader (Bio-Rad Laboratories Inc.). The sensitivity of tumor cells to 5-FU (5-FU treatment alone or in combination with LY294002) was determined by estimating the $\mathrm{IC}_{50}$ values (doses that induce $50 \%$ growth inhibition) for 5-FU from the dose-response curves. Cell growth was examined using a CCK-8 kit (Cayman, Ann Arbor, Michigan, USA). Cell growth inhibition (\%) was calculated as follows: [1-optical density (OD) values of 5-FU+/OD values of 5-FU-] x 100.

Hoechst 33258 staining. A staining solution of Hoechst 33258 was prepared immediately before use. After drug treatment, cells were incubated with Hoechst 33258 on 6-well plates (1 ml/well) for 20-30 min and washed thrice with phosphatebuffered saline. Cells were then assessed for Hoechst fluorescence using Nikon Intensilight C-HGF1 fluorescent microscope (Nikon, Tokyo, Japan) (magnification, x200).

Statistical analysis. Statistical analyses were performed using SPSS version 13.0 software (Chicago, IL, USA). The results are expressed as means and standard deviations ( \pm SD). Comparisons between groups were performed using one-way analysis of variance (ANOVA). Values of $\mathrm{P}<0.05$ were considered to indicate a statistically significant difference.

\section{Results}

$\mathrm{CD} \mathrm{H3}^{+} \mathrm{GC}$ cells confer chemoresistance to 5-FU. Investigation of the correlation between CD133 and chemoresistance to 5-FU in GC cells was performed. First, CD133+ and CD133- GC cell lines (SGC7901 and MKN45 GC cell lines) were treated with $5-\mathrm{FU}(0-1,000 \mu \mathrm{M})$. CD133+ ${ }^{+} \mathrm{GC}$ cells were found to be significantly resistant to 5-FU compared to autologous unsorted and CD133- GC cells (Fig. 1A). The $\mathrm{IC}_{50}$ values of $\mathrm{CD} 133^{+}$, unsorted and $\mathrm{CD} 133^{-}$cells were: $37.74 \pm 1.32$ to $26.39 \pm 2.04,15.80 \pm 0.14$ to $11.25 \pm 1.37$ and $5.46 \pm 0.98$ to $3.05 \pm 0.32 \mu \mathrm{M}$, respectively. Then, the presence of apoptosis was confirmed by Hoechst 33258 staining (Fig. 1B and C), which showed less frequent peripheral chromatin condensation and nuclear fragmentation in $\mathrm{CD}_{133}{ }^{+} \mathrm{GC}$ cells than unsorted and CD133- GC cells. Western blotting (Fig. 1D) and RT-PCR (Fig. 1E) were performed to detect the expression of P-gp, $\mathrm{Bcl}-2$ and Bax in GC cells. The results showed that $\mathrm{CD}_{133}{ }^{+} \mathrm{GC}$ cells had a tendency to express much higher amounts of P-gp and Bcl-2 than unsorted and CD133- cells, but lower expression of Bax. These data suggest that CD133 may contribute to the observed resistance to apoptosis of $\mathrm{CD} 133^{+} \mathrm{GC}$ cells. Notably, overexpression of $\mathrm{P}-\mathrm{gp}$ and $\mathrm{Bcl}-2$ may protect $\mathrm{CD} 133^{+}$ $\mathrm{GC}$ cells from apoptosis induced by $5-\mathrm{FU}$.

Downregulation of CD133 gene in SGC-7901 GC cells protects cells from apoptosis resulting from 5-FU. To further investigate the importance of CD133, gene silencing by RNA interference was performed. As shown in Fig. 2A, the expression of CD133 in GC cells was successfully knocked down by transfecting with CD133 siRNA. In addition, P-gp and Bcl-2 were decreased in CD133 siRNA-expressing cells compared to control siRNA-expressing cells, while the expression of Bax was increased (Fig. 2A and B). Furthermore, it was found that CD133 silencing increased the cytotoxicity of 5-FU in GC cells compared to cells without CD133 silencing (Fig. 2C). The $\mathrm{IC}_{50}$ values of control, negative control and siRNA CD133 were: $16.65 \pm 4.54,16.94 \pm 4.55$ and $9.66 \pm 2.01 \mu \mathrm{M}$, respectively. The presence of apoptosis was confirmed by Hoechst 33258 staining (Fig. 2D and E), which showed more frequent peripheral chromatin condensation and nuclear fragmentation in CD133 siRNA-expressing cells than in control siRNA cells. Taken together, these results indicate that downregulation of CD133 may enhance the cytotoxicity of 5-FU in GC cells by regulating the expression of $\mathrm{P}-\mathrm{gp}$ and $\mathrm{Bcl}-2$ family.

Activation of CD133 promotes resistance to apoptosis resulting from 5-FU. To confirm the role of CD133 in 5-FU resistance in GC cells, CD133 was activated by transfecting the CD133 gene into SGC7901 cancer cells (Fig. 3A). Western blotting (Fig. 3B and C) showed that CD133 expression was stably increased in CD133-expressing cells compared with vector control cells. Moreover, P-gp and Bcl-2 were increased in CD133-expressing cells compared to vector control cells, while the expression of Bax was decreased (Fig. 3D). In addition, the $\mathrm{IC}_{50}$ values of control, vector control and Flag-CD133 were: $8.69 \pm 1.03,8.87 \pm 1.20$ and $26.03 \pm 3.18 \mu \mathrm{M}$, respectively after treatment with 5-FU for $48 \mathrm{~h}$ (Fig. 3E), which indicated that CD133 overexpression increased resistance to 5-FU. The Hoechst 33258 staining (Fig. 3F and G) showed less frequent 
A
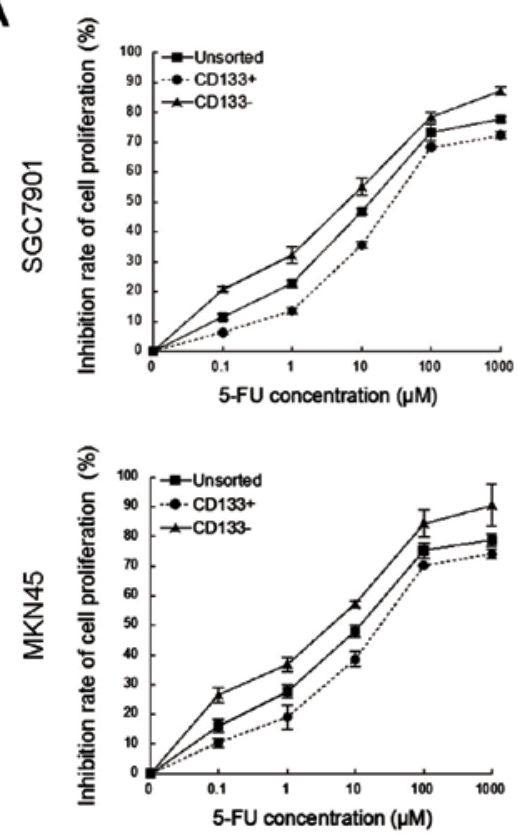

D

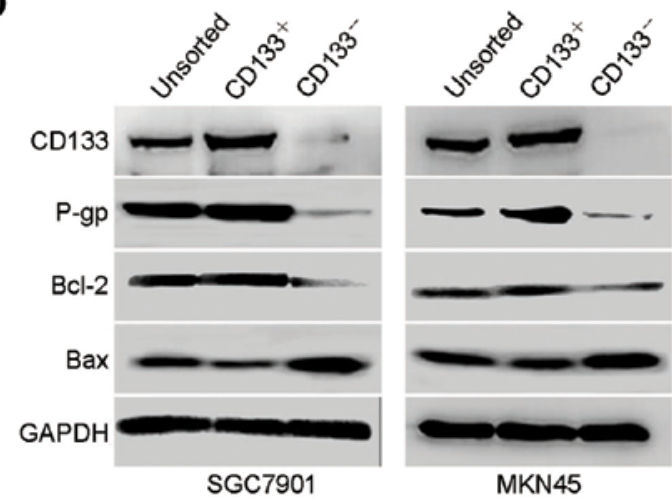

B
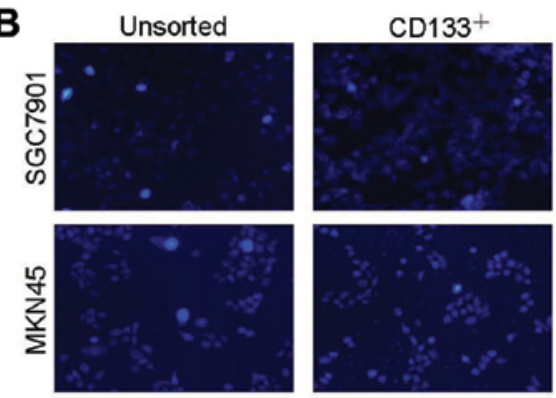

C
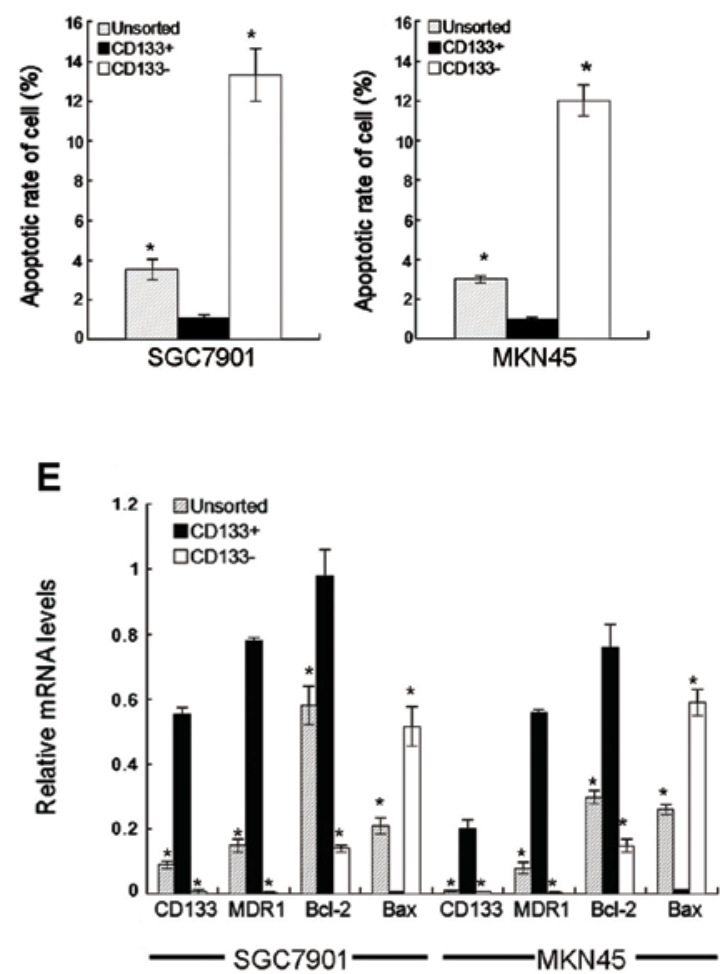

Figure 1. CD133+ cells confer resistance to 5-fluorouracil (5-FU) in gastric cancer (GC) cells. (A) SGC7901 and MKN45 cells cultured in 6-cm plates were treated with various concentrations of 5-FU $(0,1,10,100$ or $1,000 \mu \mathrm{M})$ for $48 \mathrm{~h}$. Cell Counting Kit-8 was used to analyze the inhibition of cell proliferation. Values represent means \pm standard deviation. (B and C) Hoechst 33258 staining and fluorescence microscopy showed morphological change in GC cells (magnification, x200). (D and E) Protein and messenger ribonucleic acid (mRNA) expression of CD133, P-glycoprotein, B-cell lymphoma 2 (Bcl-2) and Bcl-2-associated X proteins were determined by western blotting (D), and semi-quantitative reverse transcription-polymerase chain reaction (E), respectively. Glyceraldehyde 3-phosphate dehydrogenase protein and mRNA were used as internal controls. Control, untreated control. " $\mathrm{P}<0.05$ vs. unsorted or CD133 cells.

peripheral chromatin condensation and nuclear fragmentation in CD133-expressing cells than vector control cells. These data demonstrate that CD133 protects GC cells from 5-FU-induced cell death.

CD133 activation enhances PI3K/Akt/p70S6K activity. Recently, it was reported that Akt overexpression decreases the chemosensitivity of GC cells to 5-FU in vitro (26). Although CD133 is a downstream substrate of Akt, CD133 was shown to enhance Akt phosphorylation in several types of cancer cells $(16,22,23,27)$. Thus, the present study investigated whether CD133-induced 5-FU resistance is attributed to Akt/p70S6K activation in GC cells. As a result, it was found that although levels of total Akt proteins were similar between $\mathrm{CD} 133^{+}$ and CD133- tumor cells, the phosphorylation of Akt on S473 and p70S6K was markedly upregulated in $\mathrm{CD} 133^{+} \mathrm{GC}$ cells compared with matched CD133- GC cells (Fig. 4A and B).
Thus, these findings suggest that elevated Akt activity may be a distinctive feature of $\mathrm{CD}_{133}{ }^{+} \mathrm{GC}$ cells. Furthermore, western blotting (Fig. 4C and D) showed that CD133 activation and silencing directly increased and decreased the expressions of p-Akt and p-p70S6K, the active form of Akt and p70S6K, respectively.

CD133 enhances 5-FU resistance through PI3K/Akt/p70S6K activity. To confirm whether the positive correlation between CD133 and 5-FU resistance is mediated by Akt, the present study assessed the effects of LY294002 and EGF treatment on 5-FU-induced cytotoxicity. Western blotting (Fig. 5A-C) showed that LY294002 treatment for $48 \mathrm{~h}$ effectively blocked p-Akt and p-p70S6K expression in CD133-expressing cells, while EGF-treatment for $48 \mathrm{~h}$ reversed the effect of CD133 siRNA on these two phosphorylated proteins. Moreover, the changes of $\mathrm{P}-\mathrm{gp}$ and $\mathrm{Bcl}-2$ were in accordance with the 
A

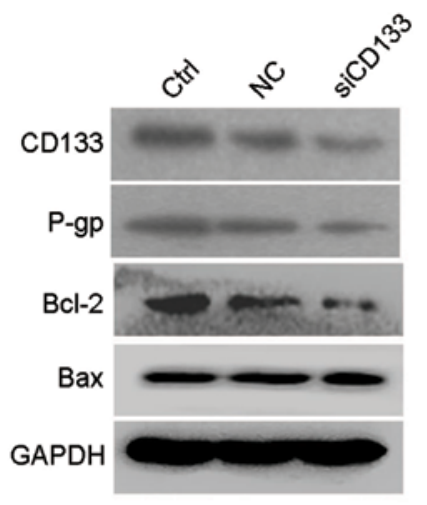

C

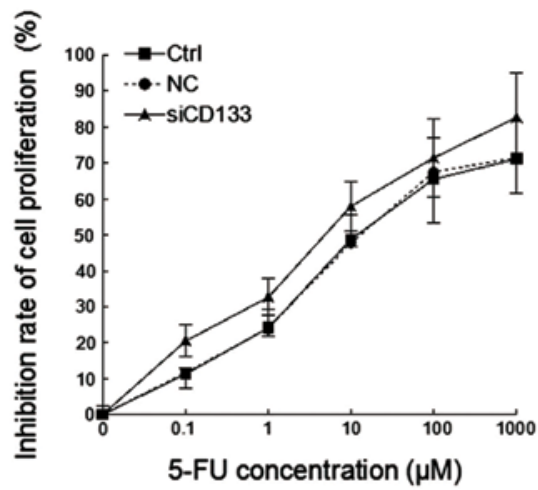

B
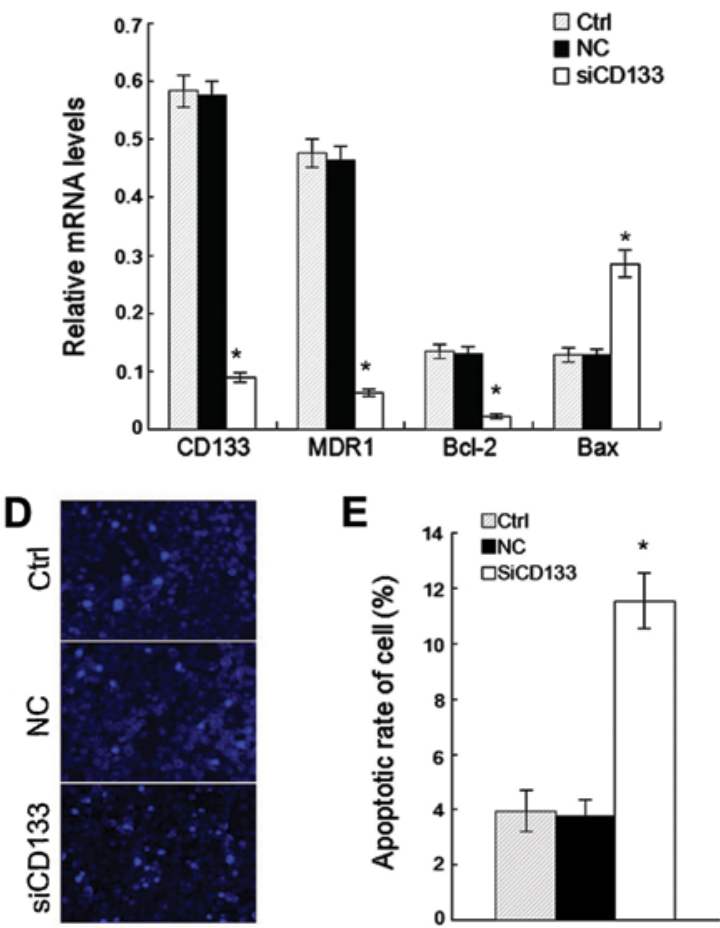

Figure 2. Effects of CD133 silencing on 5-fluorouracil (5-FU)-induced cytotoxicity in gastric cancer (GC) cell line SGC7901. Cells were transfected with non-specific small interfering ribonucleic acid (siRNA) or CD133 siRNA. (A) Western blotting and (B) reverse transcriptase-polymerase chain reaction were used to confirm the expression levels of CD133, P-glycoprotein, B-cell lymphoma 2 (Bcl-2) and Bcl-2-associated X proteins and its messenger ribonucleic acids. (C) The effect of CD133 downregulation on 5-FU cytotoxicity was analyzed as described in Fig. 1. (D and E) Hoechst 33258 staining and fluorescence microscopy showed morphological changes after CD133 downregulation in GC cells (magnification, $\mathrm{x} 200$ ). ${ }^{*} \mathrm{P}<0.05$ vs. control or negative control cells.

A
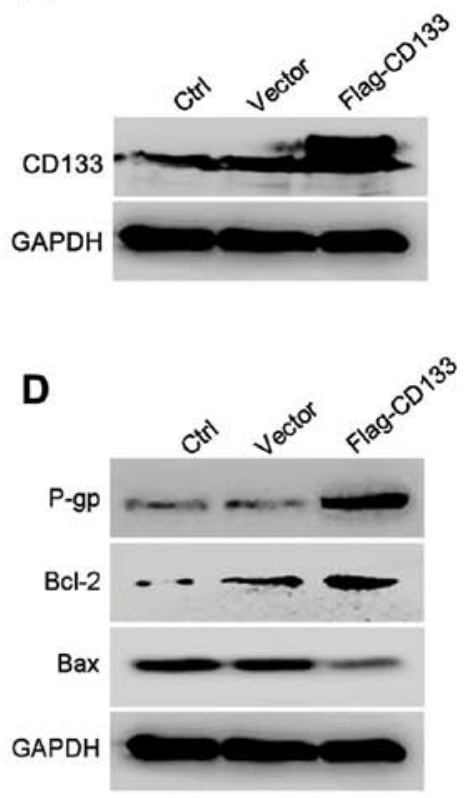

B

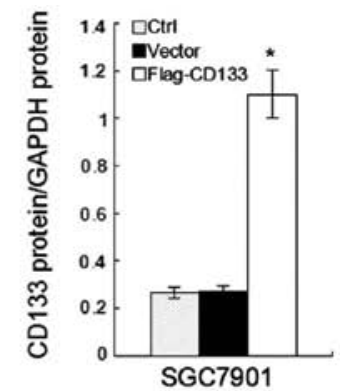

$\mathbf{E}$

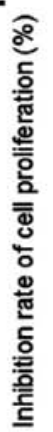

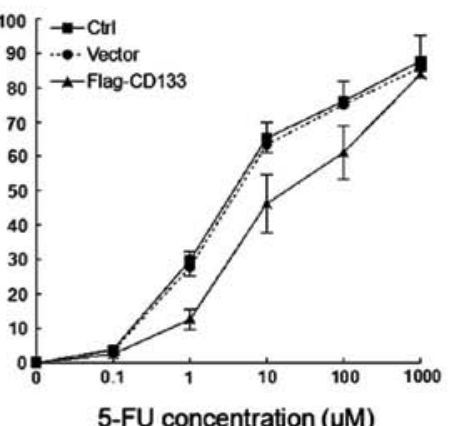

C
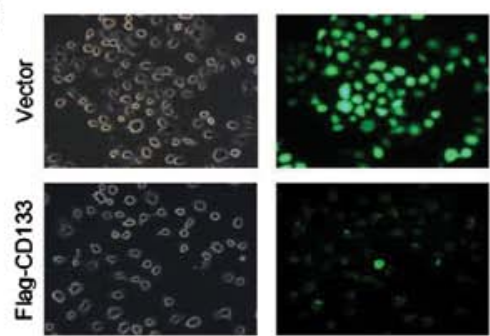

$\mathbf{F}$
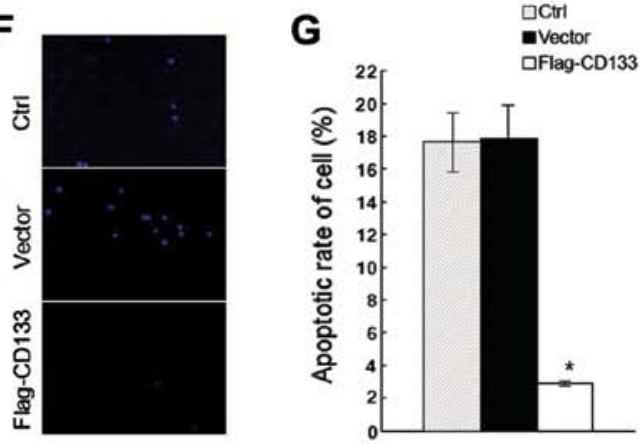

Figure 3. Effect of CD133 overexpression on 5-fluorouracil (5-FU)-induced cytotoxicity in gastric cancer (GC) cell line SGC7901. Cells were transfected with either an empty pcDNA or CD133 vector. (A-C) Effect of transfection with CD133 gene was confirmed by fluorescence microscopy showing green fluorescent protein. (D) Western blotting was used to detect the expression levels of P-glycoprotein, B-cell lymphoma 2 (Bcl-2) protein and Bcl-2associated X proteins. (E) The effect of CD133 overexpression on 5-FU cytotoxicity was analyzed as described in Fig. 1. (F and G) Hoechst 33258 staining and fluorescence microscopy showed morphological changes after CD133 overexpression in GC cells (magnification, $\mathrm{x} 200$ ). " $\mathrm{P}<0.05$ vs. control or vector control cells. 
A

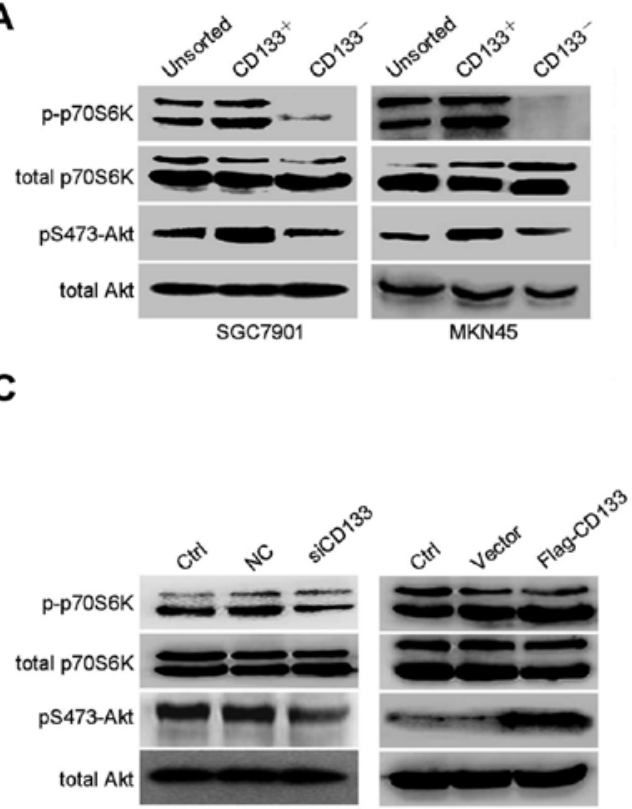

B

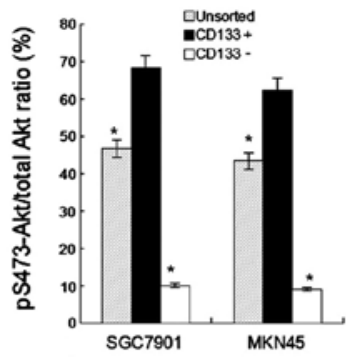

D
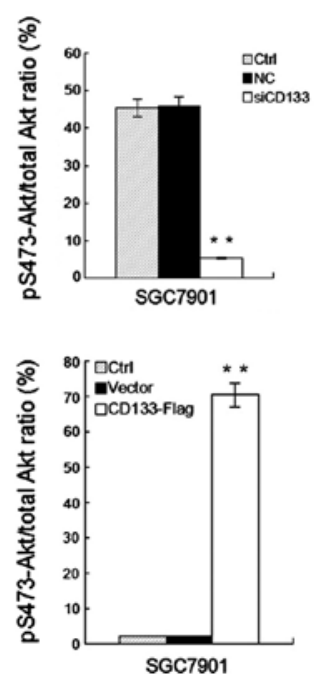
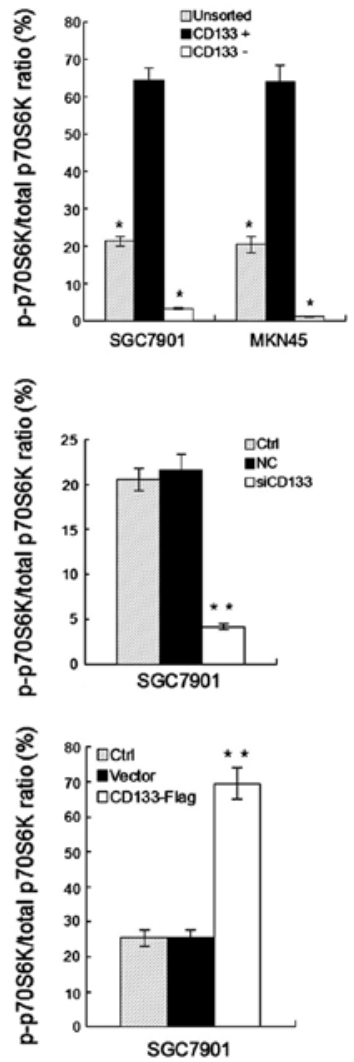

Figure 4. Effect of CD133 on the expression of phospho-Akt (p-Akt) and phospho-p70S6 kinase (p-p70S6K) in gastric cancer (GC) cell lines. Protein expression was analyzed by western blotting using specific antibodies against CD133, p-Akt, Akt, p70S6K, p-p70S6K and glyceraldehyde 3-phosphate dehydrogenase. (A and $\mathrm{B}) \mathrm{CD}_{133}{ }^{+} \mathrm{GC}$ cells were isolated by immunomagnetic cell sorting. (C and D) CD133 silencing was induced by infection with CD133 small interfering ribonucleic acid (siRNA) or non-specific siRNA and CD133 overexpression by transfection with either empty pcDNA or CD133 vector. ${ }^{*} \mathrm{P}<0.05$ vs. unsorted or $\mathrm{CD} 133^{-}$cells; ${ }^{* *} \mathrm{P}<0.05$ vs. control or vector control cells.
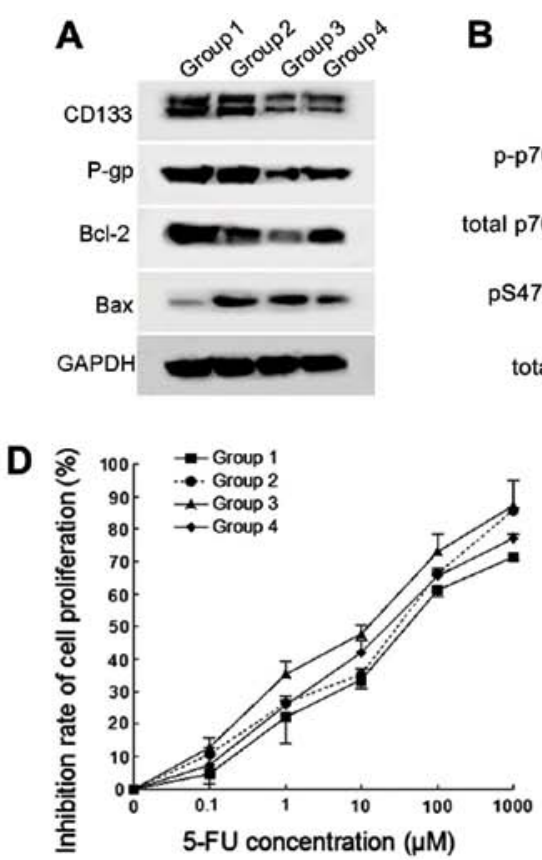

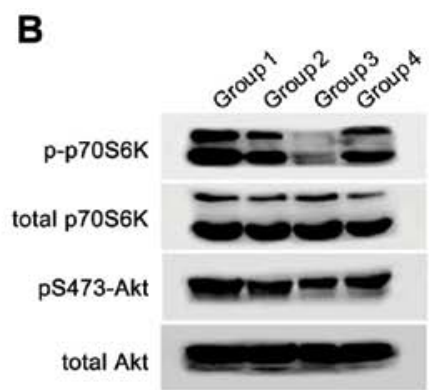

E

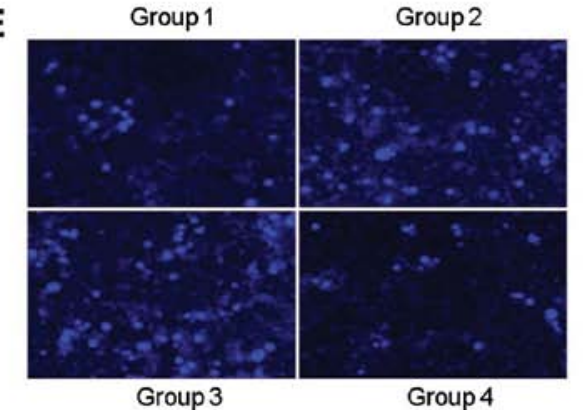

\section{C}
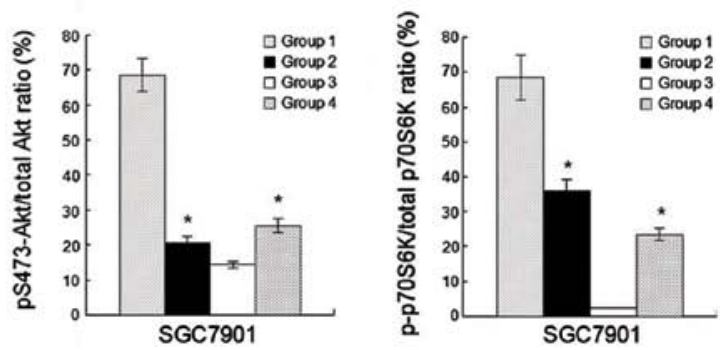

$\mathbf{F}$

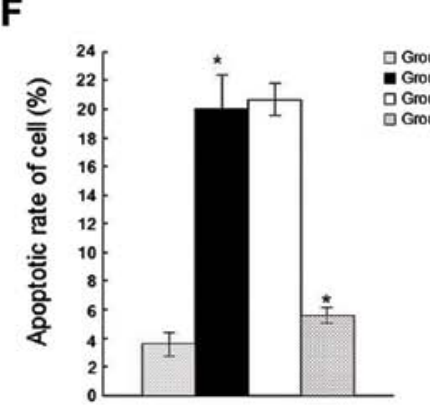

Figure 5. Effects of phosphoinositide 3-kinase (PI3K) inhibitor (LY294002) and PI3K activator [epidermal growth factor (EGF)] on phospho-Akt (p-Akt) and phospho-p70S6 kinase (p-p70S6K) expression and 5-fluorouracil resistance. (A-C) CD133 cells treated with either $10 \mu \mathrm{M} \mathrm{LY} 294002$ for $48 \mathrm{~h}\left(\mathrm{CD} 133^{+}\right)$ or $0.1 \mathrm{ng} / \mathrm{ml} \mathrm{EGF}$ for $48 \mathrm{~h}$ (CD133). Western blotting was performed with p-Akt, Akt, p70S6K, p-p70S6K, P-glycoprotein, B-cell lymphoma 2 (Bcl-2) and Bcl-2-associated X protein antibodies. (D) Cells were cultured in the presence or absence of $20 \mu \mathrm{M} \mathrm{LY} 294002 \mathrm{or} 0.1 \mathrm{ng} / \mathrm{ml} \mathrm{EGF}$ for $48 \mathrm{~h}$, and then treated with various concentrations of 5-FU $(0,1,10,100$ or $1,000 \mu \mathrm{M})$ for $48 \mathrm{~h}$. Cell Counting Kit- 8 was used to analyze the inhibition of cell proliferation. Values represent means \pm standard deviation. ( $\mathrm{E}$ and $\mathrm{F}$ ) Hoechst 33258 staining and fluorescence microscopy show morphological changes after the above treatments in gastric cancer cells (magnification, x200). Group 1, Flag-CD133; group 2, Flag-CD133+ LY294002; group 3, Flag-CD133+ CD133 small interfering ribonucleic acid (siRNA); and group 4, Flag-CD133+ ${ }^{+} \mathrm{CD} 133$ siRNA+EGF. " $\mathrm{P}<0.05$ group 2 vs. group 1; group 4 vs. group 3. 
phosphorylated levels of Akt and p70S6K. In contrast, the expression of Bax changed in the opposite direction (Fig. 5A). In addition, CD133-expressing cells treated with LY294002 showed higher 5-FU cytotoxicity, while EGF reversed the effect of CD133 siRNA on 5-FU cytotoxicity (Fig. 5D). In addition, the $\mathrm{IC}_{50}$ values of groups $1-4$ were: $27.3 \pm 3.18$, $18.01 \pm 0.18,8.63 \pm 1.22$ and $24.30 \pm 8.08 \mu \mathrm{M}$, respectively. Notably, Hoechst 33258 staining (Fig. 5E and F) illustrated that treatment with LY294002 or transfection with CD133-siRNA caused more apoptosis in 5-FU-treated CD133-expressing cells, while EGF partly reversed this change. Collectively, the above results indicate that CD133 enhances 5-FU resistance through regulation of $\mathrm{P}-\mathrm{gp}$ and $\mathrm{Bcl}-2$ family mediated by the $\mathrm{PI} 3 \mathrm{~K} / \mathrm{Akt} / \mathrm{p} 70 \mathrm{~S} 6 \mathrm{~K}$ pathway.

\section{Discussion}

Increasing evidence has shown that CD133 is not only a biomarker, but it also functions in cell growth, development and tumor biology. CD133 has been reported to be related to chemoresistance in various cancer cells (27-29). Although occurrence of resistance to chemotherapy of GC is rather frequent, involvement of CD133 in the chemoresistance of $\mathrm{GC}$ is rarely reported. The present study demonstrated the correlation between CD133 and chemoresistance in GC cells. Furthermore, this resistance may be related to CD133 with higher expression of P-gp as well as Bcl-2 and lower expression of Bax mediated by PI3K/Akt/p70S6K signaling.

In the present study, it was found that $\mathrm{CD} 133^{+} \mathrm{GC}$ cells were significantly resistant to 5-FU compared to autologous unsorted and CD133- GC cells, which was in accordance with Ma et al (15). There was also a significant difference in expression of P-gp, Bcl-2 and Bax between CD133+ and CD133- GC cells, which may explain the above phenomenon.

Gene modulation is a powerful method for analyzing gene function. In the present study, the function of CD133 in 5-FU resistance was confirmed in two GC cells by modulation of CD133 activation using two different approaches (expression of CD133 gene and CD133-siRNA). It was found that knockdown of the expression of CD133 caused corresponding changes in expression of P-gp, Bcl-2 and Bax. As a result, CD133 silencing increased cytotoxicity of 5-FU in GC cells compared to cells without CD133 silencing. In addition, activation of CD133 increased the 5-FU resistance in GC cells along with higher expression of $\mathrm{P}-\mathrm{gp}$ and $\mathrm{Bcl}-2$, which was consistent with Angelastro and Lamé (29). Collectively, these observations clearly demonstrate that CD133 is protective of 5-FU-induced cytotoxicity in GC cells and blockage of CD133 could be an effective approach to improve anticancer efficacy of 5-FU in GC patients.

It is generally accepted that Akt is a critical survival signal involved in cancer development and progression as well as chemoresistance (30). Although cancer cells acquire resistance to anticancer agents through Akt, either constitutive or induced by anticancer drugs, the molecular mechanisms underlying anticancer drug-induced Akt activation have yet to be fully elucidated. p-Akt is overexpressed in GC specimens (31). A previous study showed that Akt overexpression decreased the chemosensitivity of GC cells to 5-FU in vitro (25). Hence, the present study investigated the involvement of Akt in the CD133 regulation of 5-FU cytotoxicity in GC cells. In the present study, the phosphorylations of Akt on S473 and p70S6K was markedly upregulated in CD133+ GC cells compared with matched CD133- GC cells. Constitutive activation and silencing of CD133 increased and decreased the p-Akt and p-p70S6K expression in GC cells, respectively, suggesting that CD133 activates PI3K/Akt/p70S6K signaling. In addition, it was found that treatment of CD133 geneexpressing GC cells with the PI3K/Akt inhibitor LY294002 restored the 5-FU cytotoxicity suppressed by CD133 overexpression. Notably, PI3K/Akt activator EGF inhibited the 5-FU cytotoxicity enhanced by CD133 downregulation. Hence, CD133 and Akt appear to have similar effects on 5-FU chemoresistance in GC cells. The present study results agree with those of Wang et al (22), who showed CD133-induced PI3K/ Akt activation.

In conclusion, the results of the present study suggest that concurrent blocking of CD133 and PI3K/Akt/p70S6K pathways is an effective strategy for improving the anticancer efficacy of 5-FU. Our results provide important insight into the efficient 5-FU-design for future studies on GC treatment. Studies on the association between CD133 and chemosensitivity in GC cells using human GC specimens with animal models are warranted to verify the usefulness of this strategy.

\section{Acknowledgements}

The present study was supported by funds from the National Natural Science Foundation of China (grant no. 81101850) and the Shanghai City Board of Education (grant no. 12YZ047).

\section{References}

1. Bertuccio P, Chatenoud L, Levi F, Praud D, Ferlay J, Negri E, Malvezzi M and La Vecchia C: Recent patterns in gastric cancer: a global overview. Int J Cancer 125: 666-673, 2009.

2. Ji JF: Several surgical problems in the treatment of gastric cancer. J Pract Oncol 18: 341-346, 2003.

3. Peichev M, Naiyer AJ, Pereira D, Zhu Z, Lane WJ, Williams M, Oz MC, Hicklin DJ, Witte L, Moore MA and Rafii S: Expression of VEGFR-2 and AC133 by circulating human $\mathrm{CD}^{2} 4^{+}$cells identifies a population of functional endothelial precursors. Blood 95: 952-958, 2000

4. O'Brien CA, Pollett A, Gallinger S and Dick JE: A human colon cancer cell capable of initiating tumour growth in immunodeficient mice. Nature 445: 106-110, 2007.

5. Eramo A, Lotti F, Sette G, Pilozzi E, Biffoni M, Di Virgilio A, Conticello C, Ruco L, Peschle C and De Maria R: Identification and expansion of the tumorigenic lung cancer stem cell population. Cell Death Differ 15: 504-514, 2008.

6. Singh SK, Clarke ID, Terasaki M, Bonn VE, Hawkins C, Squire J and Dirks PB: Identification of a cancer stem cell in human brain tumors. Cancer Res 63: 5821-5828, 2003.

7. Hermann PC, Huber SL, Herrler T, Aicher A, Ellwart JW Guba M, Bruns CJ and Heeschen C: Distinct populations of cancer stem cells determine tumor growth and metastatic activity in human pancreatic cancer. Cell Stem Cell 1: 313-323, 2007.

8. Lee HH, Seo KJ, An CH, Kim JS and Jeon HM: CD133 expression is correlated with chemoresistance and early recurrence of gastric cancer. J Surg Oncol 106: 999-1004, 2012.

9. Liu G, Yuan X, Zeng Z, Tunici P, Ng H, Abdulkadir IR, Lu L, Irvin D, Black KL and Yu JS: Analysis of gene expression and chemoresistance of CD $133^{+}$cancer stem cells in glioblastoma. Mol Cancer 5: 67, 2006.

10. Baba T, Convery PA, Matsumura N, Whitaker RS, Kondoh E, Perry T, Huang Z, Bentley RC, Mori S, Fujii S, Marks JR, Berchuck A and Murphy SK: Epigenetic regulation of $C D 133$ and tumorigenicity of $\mathrm{CD} 133^{+}$ovarian cancer cells. Oncogene 28 : 209-218, 2009. 
11. Zhu Y1, Jiang B, Cai C, Wang S, Wu J and Yu J: Relationship between CD133 and chemoresistance in human gastric cancer and its associated mechanism. Zhonghua Wei Chang Wai Ke Za Zhi 17: 168-174, 2014 (In Chinese).

12. Kim R, Emi M and Tanabe K: Role of mitochondria as the gardens of cell death. Cancer Chemother Pharmacol 57: 545-553, 2006.

13. Dean M, Fojo T and Bates S: Tumor stem cells and drug resistance. Nat Rev Cancer 5: 275-284, 2005.

14. Haraguchi N, Utsunomiya T, Inoue H, Tanaka F, Mimori K, Barnard GF and Mori M: Characterization of a side population of cancer cells from human gastrointestinal system. Stem Cells 24 506-513, 2006.

15. Ma S, Lee TK, Zheng BJ, Chan KW and Guan XY: CD133+ HCC cancer stem cells confer chemoresistance by preferential expression of the Akt/PKB survival pathway. Oncogene 27: $1749-1758,2008$

16. Cardone MH, Roy N, Stennicke HR, Salvesen GS, Franke TF, Stanbridge E, Frisch S and Reed JC: Regulation of cell death protease caspase-9 by phosphorylation. Science 282: 1318-1321, 1998.

17. Brunet A, Bonni A, Zigmond MJ, Lin MZ, Juo P, Hu LS, Anderson MJ, Arden KC, Blenis J and Greenberg ME: AKT promotes cell survival by phosphorylating and inhibiting a Forkhead transcription factor. Cell 96: 857-868, 1999.

18. Curnock AP, Logan MK and Ward SG: Chemokine signalling: pivoting around multiple phosphoinositide 3-kinases. Immunology 105: 125-136, 2002.

19. Baldwin AS: Control of oncogenesis and cancer therapy

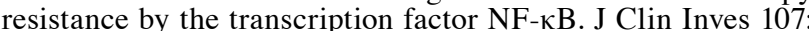
241-246, 2001.

20. Ozes ON, Mayo LD, Gustin JA, Pfeffer SR, Pfeffer LM and Donner DB: NF- $\kappa \mathrm{B}$ activation by tumour necrosis factor requires the AKT serine-threonine kinase. Nature 401: 82-85, 1999.

21. Sartelet H, Imbriglio T, Nyalendo C, Haddad E, Annabi B Duval M, Fetni R, Victor K, Alexendrov L, Sinnett D, Fabre M and Vassal G: CD133 expression is associated with poor outcome in neuroblastoma via chemoresistance mediated by the AKT pathway. Histopathology 60: 1144-1155, 2012.

22. Wang YK, Zhu YL, Qiu FM, Zhang T, Chen ZG, Zheng S and Huang J: Activation of Akt and MAPK pathways enhances the tumorigenicity of $\mathrm{CD} 133^{+}$primary colon cancer cells. Carcinogenesis 31: 1376-1380, 2010.
23. Lu RQ, Wu JG, Zhou GC, Jiang HG, Yu JW and Jiang BJ: Sorting of CD133(+) subset cells in human gastric cancer and the identification of their tumor initiating cell-like properties. Zhonghua Wei Chang Wai Ke Za Zhi 15: 174-179, 2012 (In Chinese).

24. Takaishi S, Okumura T, Tu S, Wang SS, Shibata W, Vigneshwaran R, Gordon SA, Shimada Y and Wang TC: Identification of gastric cancer stem cells using the cell surface marker CD44. Stem Cells 27: 1006-1020, 2009.

25. Shin JY, Kim JO, Lee SK, Chae HS and Kang JH: LY294002 may overcome 5-FU resistance via down-regulation of activated p-AKT in Epstein-Barr virus-positive gastric cancer cells. BMC Cancer 10: 425, 2010.

26. Wei Y, Jiang Y, Zou F, Liu Y, Wang S, Xu N, Xu W, Cui C, Xing Y, Liu Y, Cao B, Liu C, Wu G, Ao H, Zhang X and Jiang J: Activation of PI3K/Akt pathway by CD133-p85 interaction promotes tumorigenic capacity of glioma stem cells. Proc Natl Acad Sci USA 110: 6829-6834, 2013.

27. Damdinsuren B, Nagano H, Kondo M, Natsag J, Hanada $H$, Nakamura M, Wada H, Kato H, Marubashi S, Miyamoto A, Takeda Y, Umeshita K, Dono K and Monden M: TGF- $\beta 1$ induced cell growth arrest and partial differentiation is related to the suppression of Id1 in human hepatoma cells. Oncol Rep 15: 401-408, 2006

28. Zhang Q, Shi S, Yen Y, Brown J, Ta JQ and Le AD: A subpopulation of $\mathrm{CD}_{133^{+}}$cancer stem-like cells characterized in human oral squamous cell carcinoma confer resistance to chemotherapy. Cancer Lett 289: 151-160, 2010.

29. Angelastro JM and Lamé MW: Overexpression of CD133 promotes drug resistance in C6 glioma cells. Mol Cancer Res 8: $1105-1115,2010$.

30. Shimamura H, Terada Y, Okado T, Tanaka H, Inoshita S and Sasaki S: The PI3-kinase-Akt pathway promotes mesangial cell survival and inhibits apoptosis in vitro via NF- $\kappa \mathrm{B}$ and Bad. J Am Soc Nephrol 14: 1427-1434, 2003.

31. Bellacosa A, Kumar CC, Di Cristofano A and Testa JR: Activation of AKT kinases in cancer: implications for therapeutic targeting. Adv Cancer Res 11: 29-86, 2005. 